\title{
Study of the Dynamic Strain-Induced Transformation Process of a Low-Carbon Steel: Experiment and Finite Element Simulation
}

\author{
Lei He, ${ }^{1}$ Ruijie Ruan, ${ }^{1}$ Chen Lin, ${ }^{1}$ Ting Dai, ${ }^{1}$ Xianjun $\mathrm{Hu}^{2}{ }^{2}$ \\ Bruce W. Krakauer, ${ }^{3}$ and Mingfang $\mathrm{Zhu}^{1}$ \\ ${ }^{1}$ Jiangsu Key Laboratory for Advanced Metallic Materials, School of Materials Science and Engineering, Southeast University, \\ Nanjing, Jiangsu 211189, China \\ ${ }^{2}$ Institute of Research of Iron \& Steel, Shasteel, Zhangjiagang, Jiangsu 215625, China \\ ${ }^{3}$ AO Smith Corporate Technology Center, Milwaukee, WI 53224, USA
}

Correspondence should be addressed to Mingfang Zhu; zhumf@seu.edu.cn

Received 12 August 2016; Revised 9 November 2016; Accepted 15 November 2016

Academic Editor: Qiang Wang

Copyright (C) 2016 Lei He et al. This is an open access article distributed under the Creative Commons Attribution License, which permits unrestricted use, distribution, and reproduction in any medium, provided the original work is properly cited.

\begin{abstract}
The microstructures and mechanical properties of a low-carbon steel, hot-rolled by a six-pass dynamic strain-induced transformation (DSIT) process, with different start rolling temperatures, are studied by combining experiments and finite element simulations. The start rolling temperatures of the last three passes are about $10^{\circ} \mathrm{C}$ higher and $20^{\circ} \mathrm{C}$ lower than the $\mathrm{A}_{\mathrm{r} 3}$ temperature, for Processes 1 and 2, respectively. The results show that as the rolling process proceeds, rolling forces increase, while slab temperatures decrease. Before starting Pass 4, the temperature of the slab center is higher than that of the slab surface. During Pass 4 to Pass 6 , however, the temperatures of the slab center and surface are nearly identical but fluctuate remarkably due to the large reduction rate. The simulated maximum rolling force and start rolling temperature of each pass agree reasonably with the experimental measurements. It is found that the simulated start temperatures of the slab center in the last three passes are about $5 \sim 25^{\circ} \mathrm{C}$ higher than the $\mathrm{A}_{\mathrm{r} 3}$ temperature for Process 1, and the DSIT condition is better satisfied for Process 2 . As a result, Process 2 produces finer grain sizes and higher yield strengths than Process 1.
\end{abstract}

\section{Introduction}

It is well recognized that grain refinement of steels leads to higher strength and toughness. The dynamic strain-induced transformation (DSIT) process is an effective technique to produce a fine grain microstructure by heavy deformation within a temperature range around the austenite $(\gamma)$ to ferrite $(\alpha)$ transformation start temperature, $\mathrm{A}_{\mathrm{r} 3}$ [1]. DSIT hot rolling of steels is also known to be a complicated thermomechanical process, during which steels will experience both deformation and dynamic phase transformation $[2,3]$. The microstructures and properties of the steel sheets produced by the DSIT process are impacted by several variables, such as rolling force and temperature, reduction rate, rolling pass and cooling rate $[4,5]$. An understanding of rolling force, temperature field, and stress-stain field of steels is necessary to optimize the DSIT process; however, the experimental data that can be measured during rolling processes are limited [6]. For example, it is impossible to obtain detailed information about the evolution of the temperature and stress-strain fields. Recently, the combination of physical metallurgy with computer simulation techniques, such as the finite element method (FEM), has been successfully used to investigate the effect of hot rolling process variables on the microstructures and properties of steels [7, 8]. Song et al. [7] developed a coupled two-dimensional elasticplastic thermal-mechanical model to simulate the hot ring rolling process, providing quantitative information regarding the ring shape, temperature, stress, and strain distributions. Wang et al. [8] studied the multipass continuous rolling process by using nonlinear rigid-viscoplastic FEM. However, limited work has so far been reported regarding applying FEM simulations to analyze the DSIT hot rolling process of steels. 
TABLE 1: Start temperatures and reduction rates of the DSIT hot rolling process.

\begin{tabular}{lccccccc}
\hline & Process & Pass 1 & Pass 2 & Pass 3 & Pass 4 & Pass 5 & Pass 6 \\
\hline Start temperature $\left({ }^{\circ} \mathrm{C}\right)$ & 1 & 1003 & 1007 & 1005 & 845 & 844 & 834 \\
& 2 & 1026 & 1021 & 1009 & 822 & 822 & 816 \\
Reduction rate $(\%)$ & & 25.0 & 25.0 & 28.9 & 53.1 & 60.0 & 58.3 \\
\hline
\end{tabular}

In this work, a low-carbon steel was hot rolled using a six-pass DSIT process. The rolling force, temperature field, and stress-strain field of the steel during DSIT were analyzed using the FEM software Deform. The microstructures and mechanical properties of the steel sheets, produced by the DSIT process with different start rolling temperatures, were examined and compared. Based on the results of experiments and FEM simulations, the mechanism of the DSIT process is discussed.

\section{Experiment and Simulation}

The material studied in the present work is a low-carbon steel with the composition of $0.081 \mathrm{wt} \% \mathrm{C}, 1.23 \mathrm{wt} \% \mathrm{Mn}$, $0.49 \mathrm{wt} \% \mathrm{Si}, 0.052 \mathrm{wt} \% \mathrm{P}$, and $0.0055 \mathrm{wt} \% \mathrm{~S}$. The steel was produced using laboratory hot-rolling equipment at the Institute of Research of Iron \& Steel, Shasteel. Ingots were die cast after melting in a vacuum induction furnace. Then, the ingots were forged to produce slabs with dimensions of $160 \mathrm{~mm} \times 160 \mathrm{~mm} \times 80 \mathrm{~mm}$. Before hot rolling using a sixpass DSIT process, the slabs were reheated to $1150^{\circ} \mathrm{C}$ for $2 \mathrm{~h}$. The final rolled steel sheet has the thickness of around $4.0 \mathrm{~mm}$.

To obtain a fine grain size by employing the $\gamma-\alpha$ phase transformation-induced dynamic-strain mechanism, the start rolling temperature of the last three passes, namely, the fourth to sixth passes of the DSIT process, should be close to the $\mathrm{A}_{\mathrm{r} 3}$ temperature. Differential scanning calorimetry (DSC) measurements were made to determine the $A_{r 3}$ temperature of the studied steel. The $\mathrm{A}_{\mathrm{r} 3}$ temperature obtained by DSC measurement is $834.2^{\circ} \mathrm{C}$. Quenching experiments were performed to confirm the $\mathrm{A}_{\mathrm{r} 3}$ temperature. The samples used for quenching experiments were heated at $960^{\circ} \mathrm{C}$ for $15 \mathrm{~min}$ to ensure complete austenization. Then, the samples were air cooled to the targeted quench temperatures and subsequently water quenched.

The temperature variations during the hot rolling process are quite complicated. On the one hand, the temperature of the slab surface will be lower than the slab center, due to heat loss from the slab surfaces. On the other hand, the heavy deformation might generate heat, leading to the slab surface and center temperatures increasing $[9,10]$. In addition, the start rolling temperature for process control is the slab surface temperature measured with an infrared pyrometer, since basing the process on the actual temperatures inside of a slab is not technically feasible. These factors create an uncertainty in determining the start rolling temperature of the hot rolling process. To deal with this uncertainty, two sets of the DSIT hot rolling processes with different start temperatures for Pass 4 to Pass 6 were performed. Table 1 presents the start

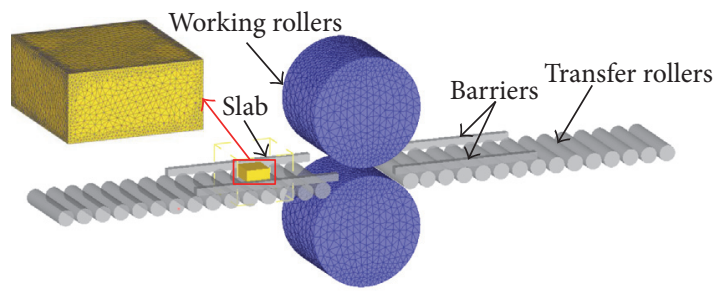

FIGURE 1: Geometric model, relative positions of the slab, working rollers and transfer rollers, and 3D FE mesh generation of the slab and rollers.

temperature measured from the center of the slab's upper surfaces and reduction rate of each pass. After finishing Pass 6 , the rolled steel sheet was water-cooled to around $500^{\circ} \mathrm{C}$ and then air-cooled to room temperature.

Standard tensile specimens were prepared (ASTM A37005). Tensile tests were conducted using a CMT5105 tensile machine with a crosshead speed of $6 \mathrm{~mm} / \mathrm{min}$. The microstructures were observed with a XL30 scanning electron microscope (SEM). The average grain sizes of the samples were measured with the ImageTool software [11].

The FEM simulations of the two DSIT rolling processes are conducted using the commercial software Deform3D. First, the geometric model is produced, in which the dimensions of the slabs, working rollers, transfer rollers, and barriers are identical with those of the experiments. Then, the three-dimensional (3D) FE mesh generation is performed for the slab and working rollers. Each working roller consists of 10,000 FE mesh unites. An absolute mesh method with maximum element size less than $6 \mathrm{~mm}$ and size ratio of 2 is used to generate the mesh of the slabs to insure the precision and efficiency of the simulations, simultaneously. Figure 1 shows the geometric model, relative positions of the slab, working rollers and transfer rollers, and 3D FE mesh generation of the slab and working rollers.

The material selected for the simulation is the AISI-1015 steel due to the similar compositions of the experiment steel and the AISI-1015 steel. The process variables, including the interval time between each pass, the rolling speeds, and the reduction rates of each pass, are set to be the same as the actual rolling processes. The rolling speeds of each pass are constant and equal to $1.2 \mathrm{~m} / \mathrm{s}$. The reduction rates of each pass and the interval time between each pass of the two processes are given in Tables 1 and 2, respectively.

Other simulation parameters are taken as follows. The coefficient of shear friction is 0.7 . The convective heat transfer coefficient between the slab and air is $0.02 \mathrm{kw} / \mathrm{m}^{2} \cdot{ }^{\circ} \mathrm{C}$. The heat transfer coefficient between the slab and rollers is 
TABLE 2: Interval time between each pass of the two DSIT processes.

\begin{tabular}{cccccccc}
\hline & Process & Before rolling & Pass 1 to Pass 2 & Pass 2 to Pass 3 & Pass 3 to Pass 4 & Pass 4 to Pass 5 & Pass 5 to Pass 6 \\
\hline \multirow{2}{*}{ Time (s) } & 1 & 63 & 6 & 7 & 115 & 22 & 14 \\
& 2 & 66 & 9 & 7 & 144 & 24 & 14 \\
\hline
\end{tabular}

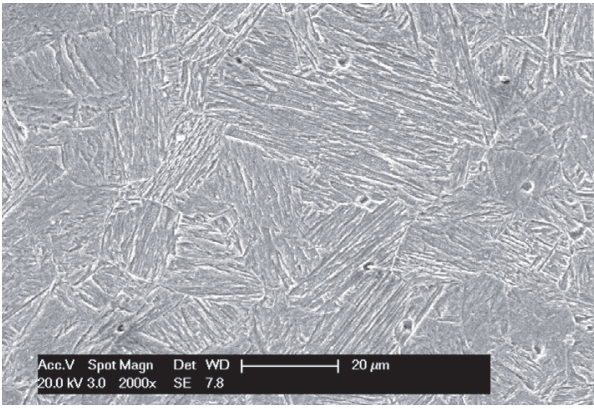

(a)

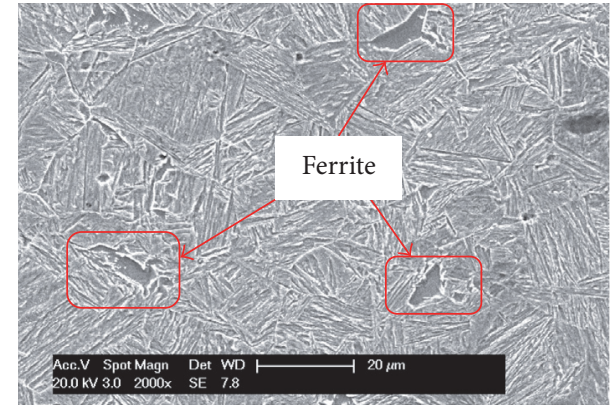

(b)

Figure 2: Microstructures of the quenched steels: (a) $845^{\circ} \mathrm{C}$ and (b) $830^{\circ} \mathrm{C}$.

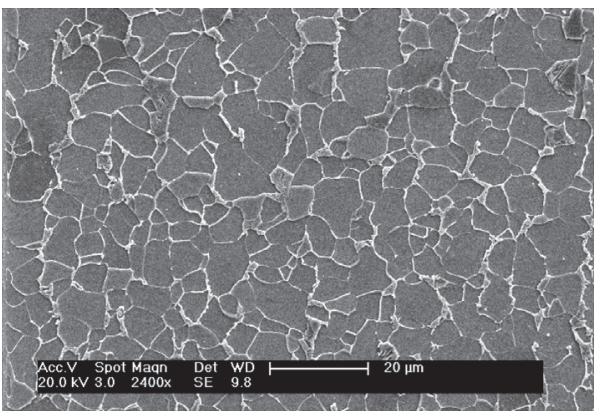

(a)

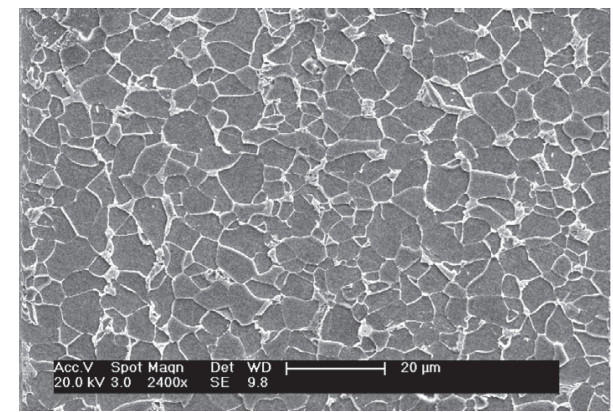

(b)

Figure 3: SEM images of (a) Sample 1 (Process 1) and (b) Sample 2 (Process 2).

$9.5 \mathrm{kw} / \mathrm{m}^{2} \cdot{ }^{\circ} \mathrm{C}$. The thermal emissivity is 0.7 . The environmental temperature and the initial temperature of rollers are assumed to be $25^{\circ} \mathrm{C}$. The initial temperature of the slab is $1150^{\circ} \mathrm{C}$.

\section{Results and Discussion}

As described in Section 2, quenching experiments were conducted to confirm the $\mathrm{A}_{\mathrm{r} 3}$ temperature using DSC measurements. Figure 2 shows the microstructures of the samples after heating at $960^{\circ} \mathrm{C}$ for $15 \mathrm{~min}$ and then air-cooling to $845^{\circ} \mathrm{C}$ and $830^{\circ} \mathrm{C}$, respectively, and subsequently being waterquenched. It can be seen that the microstructure quenched from $830^{\circ} \mathrm{C}$ consists of martensite and a small quantity of ferrite, while there is no ferrite when quenched from $845^{\circ} \mathrm{C}$. Accordingly, the $\mathrm{A}_{\mathrm{r} 3}$ temperature is in the range of $830 \sim$ $845^{\circ} \mathrm{C}$, which is consistent with the DSC test results.

Figure 3 shows SEM images of the as-rolled samples obtained from the two processes listed in Table 1. It can be seen that the microstructures of the two samples mainly consist of ferrite. The grain size of Sample $2(4.3 \mu \mathrm{m})$ is finer than that of Sample $1(5.2 \mu \mathrm{m})$. The yield strengths are $363.2 \mathrm{MPa}$ and $395.1 \mathrm{MPa}$, and the tensile strengths are 525.9 MPa and 542.9 MPa for Samples 1 and 2, respectively.

Figure 4 presents a comparison of the simulated and experimental maximum rolling force of each pass obtained from Process 2. As shown, the maximum rolling forces in Pass 4 to Pass 6 are much higher than that in Pass 1 to Pass 3, due to the fact that as the rolling proceeds, the slab temperature decreases, and reduction rate increases.

Figure 5 shows the evolution of the simulated rolling force in Pass 4 of Process 2. The rolling force increases suddenly from zero when the slab first contacts the roller and then fluctuates in a certain range. The rolling force decreases rapidly to zero when the slab exits the roller. The maximum rolling forces obtained by simulation and experiment are 6.33 $\times 10^{6} \mathrm{~N}$ and $6.69 \times 10^{6} \mathrm{~N}$, respectively.

Figure 6 shows, for Process 2, the simulated time evolutions of the temperatures in the slab center and surface. The simulated surface temperature is selected from the center of the slab's upper surface, which is identical with the measurement region of the experimental process. As shown, 


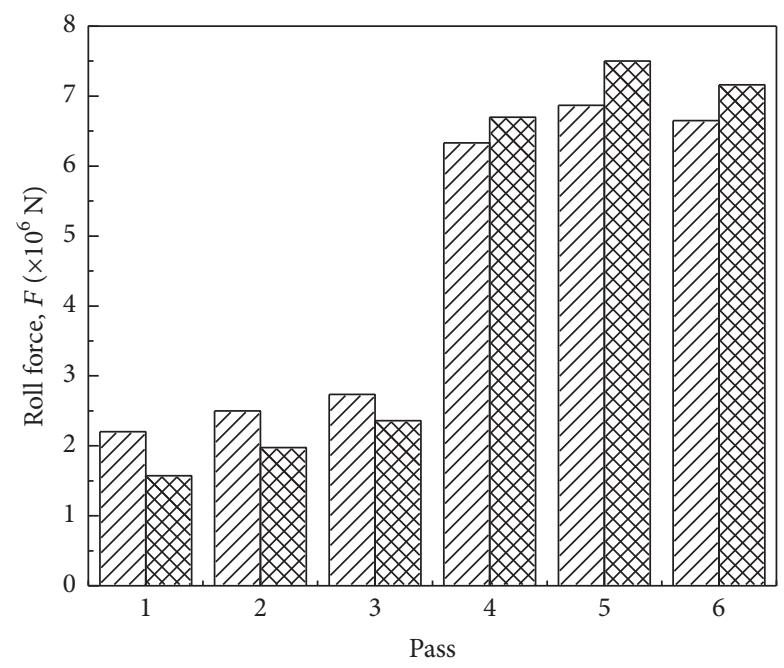

ZIIJ Simulation

Experiment

FIGURE 4: Comparison of simulated and experimental maximum rolling force of each pass in Process 2.

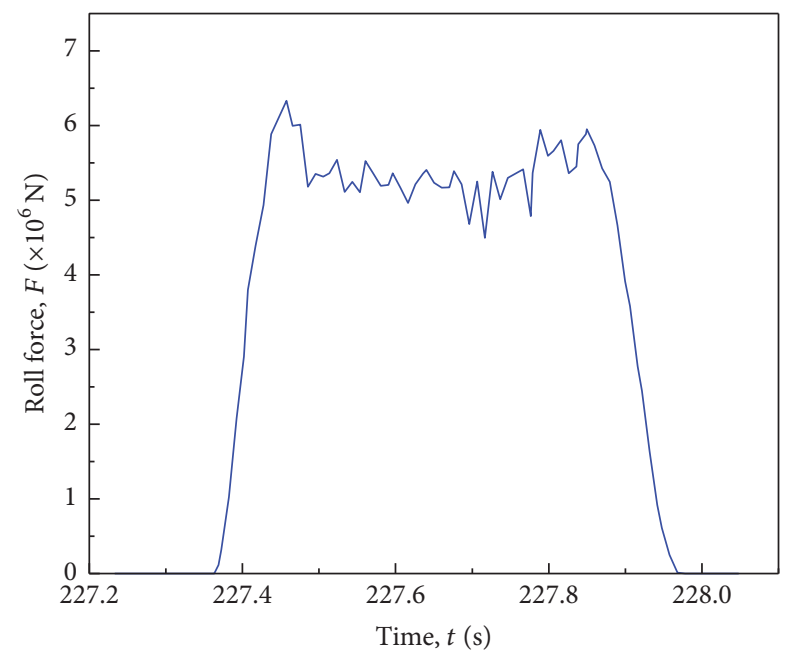

FIgUre 5: Simulated rolling force in Pass 4 of Process 2.

when the time is less than about $100 \mathrm{~s}$ (Pass 1 to Pass 3), the temperature in the slab center is higher than that of the surface by about $40 \sim 100^{\circ} \mathrm{C}$, which is mainly due to the higher heat dispersion of the slab surface than that of the slab center, when the slab is thick. The temperature drop of the slab surface is caused by both heat radiation and heat convection between the contact surfaces of slab/air and slab/roller, while the temperature drop of the slab center is due to heat transfer from the slab center to surface.

During the first three passes proceeding in the time of $66 \sim$ $100 \mathrm{~s}$, the temperatures of slab and rollers are about $1000^{\circ} \mathrm{C}$ and $25^{\circ} \mathrm{C}$, respectively. The large temperature difference between the slab and rollers results in high heat convection between the contact surfaces of the slab and rollers and thus

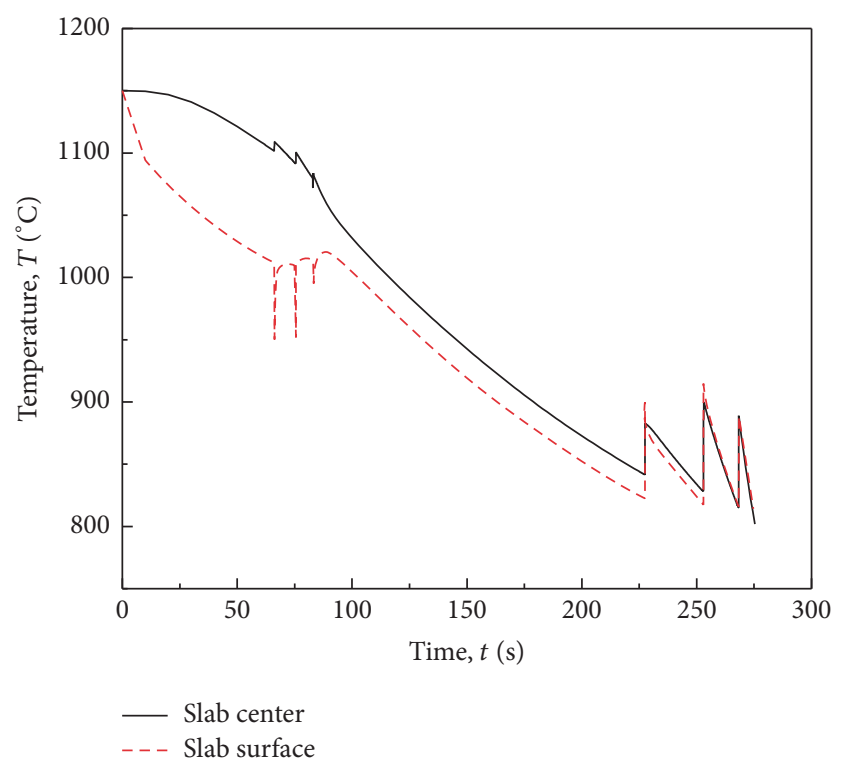

FIGURE 6: Simulated temperatures of slab center and surface varying with time in Process 2.

the sudden temperature drop of the slab surface. During rolling, the slab temperature is also impacted by the heat generated by deformation. In the third pass, the effect of deformation heat becomes evident, which offsets some heat loss from the slab surfaces due to convection. Therefore, the degree of the temperature drop on the slab surface of the third pass is lower than that of Pass 1 and Pass 2. Regarding the temperature variation profile of the slab center, owing to the relatively low heat transfer between the slab center and surface, the effect of deformation heat becomes dominant, leading to slight temperature fluctuations in the slab center during the first three passes.

During the time of 100 225 s that is the interval between Pass 3 and Pass 4, the temperature difference between slab center and surface is nearly constant at about $25^{\circ} \mathrm{C}$. During the last three passes proceeding in the period of $225 \sim 275 \mathrm{~s}$, the temperatures of slab surface and center become more equal, because of the low slab temperature and thin slab thickness. It can also be seen that, in each pass, there are temperature fluctuations in the temperature profiles of the slab center and surface. However, temperatures fluctuate more remarkably in Pass 4 to Pass 6 , in a range of about $810 \sim 900^{\circ} \mathrm{C}$, owing to the heat produced by the large deformation (53\% 60\%).

Figure 7 presents a comparison of the simulation and experimental measurement for the start temperatures in each pass in Process 2. It can be seen that at the beginning of the process, there is an obvious temperature difference between the slab center and surface. As rolling process proceeds, the temperatures of the slab center and surface trend to be close. The simulated surface temperatures agree reasonably well with those measured by experiment.

Figure 8 shows a comparison of the experimental maximum rolling forces in Pass 4 to Pass 6 of the Process 1 and Process 2. It can be found that the slab in Process 2 bears higher rolling forces than that of the slab in Process 1. In 


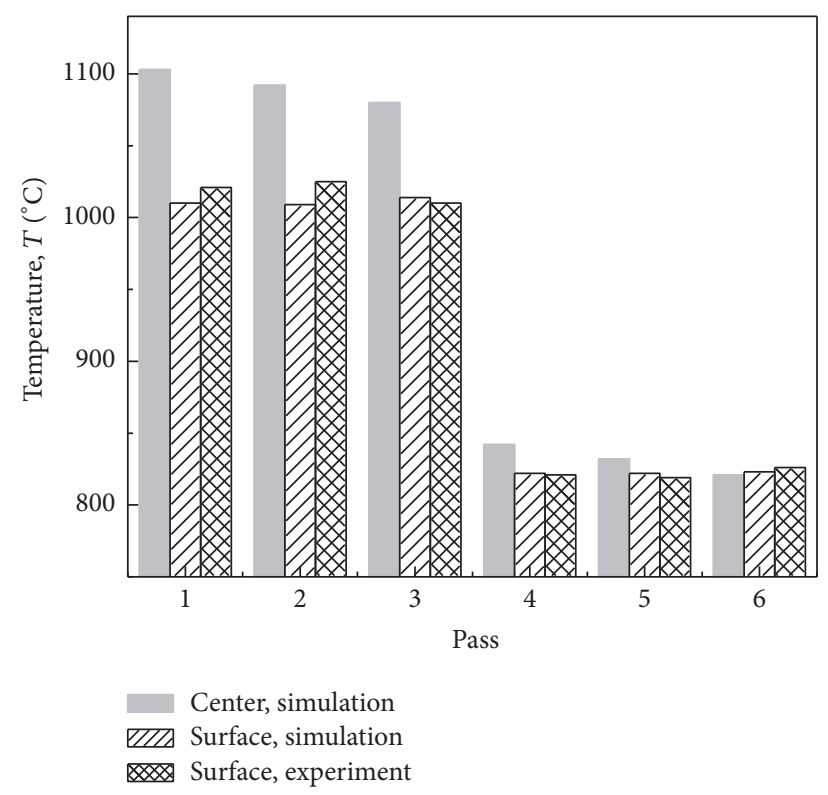

FIGURE 7: Comparison of simulated and experimental start temperatures of each pass in Process 2.

particular, the difference in rolling forces in Pass 4 between the two processes reaches $5.03 \times 10^{5} \mathrm{~N}$. This difference may be caused by the relatively higher temperature of the slab in Process 1, as higher temperatures result in lower deformation resistance. A comparison of the simulated start temperatures of the slab center in the last three passes of the two processes is shown in Figure 9. It can be seen, however, that the start temperatures of slab center in the last three passes of Process 1 are in the range of $840 \sim 860^{\circ} \mathrm{C}$ that is higher than the $\mathrm{A}_{\mathrm{r} 3}$ temperature. On the other hand, the start temperatures in the last three passes of Process 2 are controlled in the range of $820 \sim 845^{\circ} \mathrm{C}$ that is close to the $\mathrm{A}_{\mathrm{r} 3}$ temperature.

According to the simulation results of the two processes, it can be seen that when controlling the start rolling temperatures of the slab surface in the last three passes at about $820^{\circ} \mathrm{C}$, the conditions of DSIT, namely, imposing heavy deformation on the slab near $A_{r 3}$, can be better satisfied. Large deformation at around $\mathrm{A}_{\mathrm{r} 3}$ accumulates defects in both austenite grains and grain boundaries. These defects, on the one hand, increase the Gibbs energy of austenite, which decreases the stability of austenite. On the other hand, they also can become effective nucleation sites for ferrite [12]. Tong et al. [13] indicated that large deformation at near $\mathrm{A}_{\mathrm{r} 3}$ can reduce the critical radius of ferrite nuclei. These factors promote the transformation of austenite to ferrite. Therefore, a large amount of ferrite is formed during the DSIT. These formed ferrite grains will become further refined by repeated dynamic recrystallization in the subsequent deformation process. However, when setting the start rolling temperatures of the slab surface in the last three passes near $840^{\circ} \mathrm{C}$, the relatively higher temperature of slab center in Pass 4 leads the conditions of DSIT not to being satisfied. Therefore, Process 2 produced the finer microstructure and higher yield strength than Process 1. It should be noted that, during the

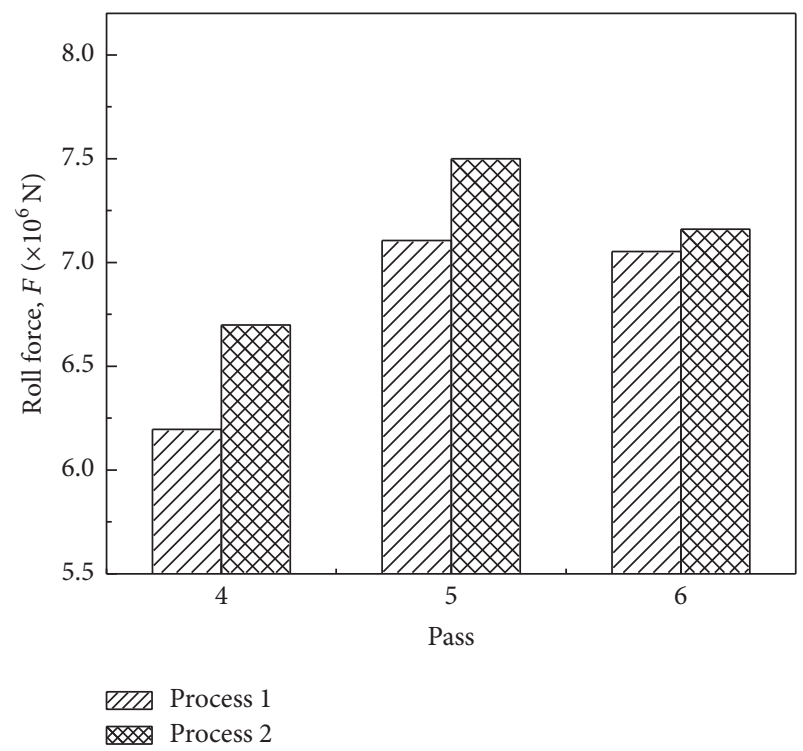

FIGURE 8: Comparison of experimental maximum rolling forces in the last three passes of the two processes.

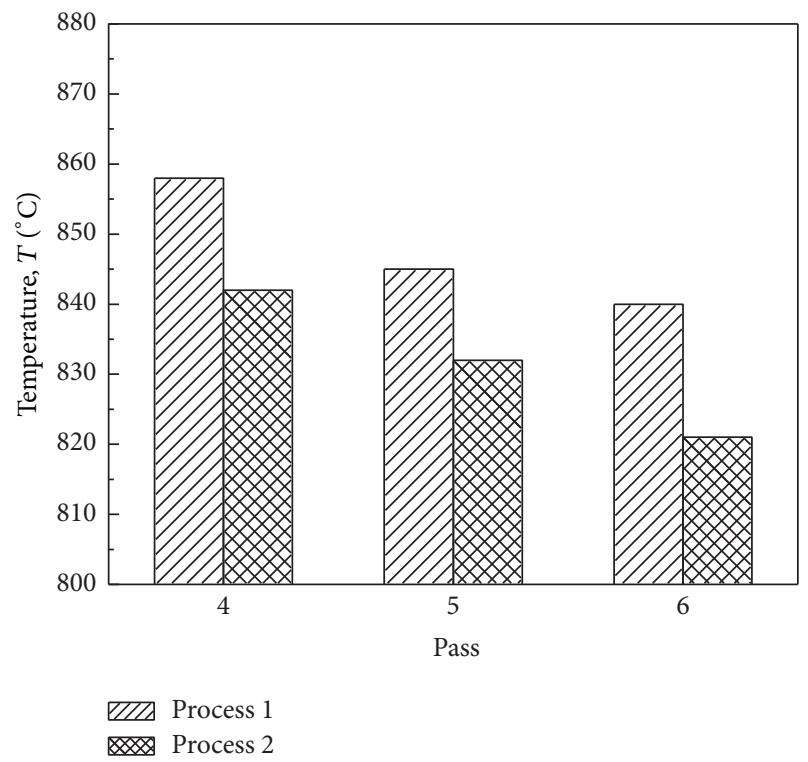

Figure 9: Comparison of simulated start temperatures in the slab center of the two processes.

DSIT rolling process, the deformed austenite does not have the same potential to transform to ferrite [14]. Part of the deformed austenite does not experience the dynamic straininduced transformation, and most of the residual austenite will transform to ferrite by static phase transformation in the water cooling process after rolling. It is known that the ferrite formed by DSIT has a finer grain size, while the grain size of the ferrite transformed by static phase transformation is relatively coarse [15], which may explain the nonuniform microstructure of the as-rolled steel produced in Process 2. 


\section{Conclusions}

A six-pass dynamic strain-induced transformation (DSIT) process with different start rolling temperatures of a lowcarbon steel was studied by combining experiments and finite element simulations. The start rolling temperatures of the last three passes for the Processes 1 and 2 were about $10^{\circ} \mathrm{C}$ higher and about $20^{\circ} \mathrm{C}$ lower than $\mathrm{A}_{\mathrm{r} 3}$, respectively. The results are summarized as follows:

(1) When controlling the start temperatures of the last three passes about $20^{\circ} \mathrm{C}$ lower than $A_{r 3}$, a finer microstructure $(4.3 \mu \mathrm{m}$ grain size $)$ and higher yield strength $(395.1 \mathrm{MPa})$ of a low-carbon steel were produced by the DSIT process.

(2) In Pass 1 to Pass 3, the temperature of the slab center is about $40 \sim 100^{\circ} \mathrm{C}$ higher than that of the slab surface. In the last three passes, the temperatures of the slab center and surface are nearly identical but fluctuate remarkably due to the large reduction rate.

(3) The maximum rolling forces in Pass 4 to Pass 6 are much higher than that in Pass 1 to Pass 3, due to the reduced slab temperature and increased reduction rate in the last three passes. The simulated maximum rolling forces and start temperatures of each pass agree reasonably well with those obtained experimentally.

(4) The simulated start temperatures of the slab center in the last three passes are about $840 \sim 860^{\circ} \mathrm{C}$ and about $820 \sim 845^{\circ} \mathrm{C}$, which are about $5 \sim 25^{\circ} \mathrm{C}$ higher than and close to the $\mathrm{A}_{\mathrm{r} 3}$ temperature (about $835^{\circ} \mathrm{C}$ ) for Processes 1 and 2, respectively. Thus, the DSIT condition is better satisfied for Process 2. It is known that the ferrite formed by DSIT has a finer and more uniform grain size than that by static phase transformation. Accordingly, Process 2 produced finer grain size and higher yield strengths than Process 1.

\section{Competing Interests}

The authors declare that they have no competing interests.

\section{Acknowledgments}

This work was financially supported by the AO Smith Corporate Technology Center, USA, and NSFC (Grant no. 51371051).

\section{References}

[1] Y. Q. Weng, Ultrafine Grained Steel, Metallurgical Industry Press, Beijing, China, 2008.

[2] P. S. Bandyopadhyay, S. K. Ghosh, S. Kundu, and S. Chatterjee, "Evolution of microstructure and mechanical properties of thermomechanically processed ultrahigh-strength steel," Metallurgical and Materials Transactions A, vol. 42, no. 9, pp. 27422752, 2011.
[3] M. R. Hickson, P. J. Hurley, R. K. Gibbs, G. L. Kelly, and P. D. Hodgson, "The production of ultrafine ferrite in lowcarbon steel by strain-induced transformation," Metallurgical and Materials Transactions A, vol. 33, no. 4, pp. 1019-1026, 2002.

[4] M. Jahazi and B. Egbali, "The influence of hot rolling parameters on the micro structure and mechanical properties of an ultrahigh strength steel," Journal of Materials Processing Technology, vol. 103, no. 2, pp. 276-279, 2000.

[5] Z. Li and D. Wu, "Influence of hot rolling conditions on the mechanical properties of hot rolled TRIP steel," Journal Wuhan University of Technology, vol. 23, no. 1, pp. 74-79, 2008.

[6] L. C. Yang, J. X. Hu, L. W. Ning, and A. Romagos, "Simulation of different forming mode of wire based on thermo-mechanical coupling method," Mechanika, vol. 17, no. 6, pp. 674-680, 2011.

[7] J. L. Song, A. L. Dowson, M. H. Jacobs, J. Brooks, and I. Beden, "Coupled thermo-mechanical finite-element modelling of hot ring rolling process," Journal of Materials Processing Technology, vol. 121, no. 2-3, pp. 332-340, 2002.

[8] M.-T. Wang, X.-L. Zang, X.-T. Li, and F.-S. Du, "Finite element simulation of hot strip continuous rolling process coupling microstructural evolution," Journal of Iron and Steel Research International, vol. 14, no. 3, pp. 30-36, 2007.

[9] M. P. Phaniraj, B. B. Behera, and A. K. Lahiri, "Thermo-mechanical modeling of two phase rolling and microstructure evolution in the hot strip mill: part I. Prediction of rolling loads and finish rolling temperature," Journal of Materials Processing Technology, vol. 170, no. 1-2, pp. 323-335, 2005.

[10] Z.-C. Sun, H. Yang, and X.-Z. Ou, "Thermo-mechanical coupled analysis of hot ring rolling process," Transactions of Nonferrous Metals Society of China, vol. 18, no. 5, pp. 1216-1222, 2008.

[11] "Image Tool Program Developed at the University of Texas Health Science Center at San Antonio," 2002, http://compdent .uthscsa.edu/dig/itdesc.html.

[12] L. Hao, M. Sun, N. Xiao, and D. Li, "Characterizations of dynamic strain-induced transformation in low carbon steel," Journal of Materials Science \& Technology, vol. 28, no. 12, pp. 1095-1101, 2012.

[13] M. M. Tong, J. Ni, Y. T. Zhang, D. Z. Li, and Y. Y. Li, "Monte Carlo-method simulation of the deformation-induced ferrite transformation in the Fe-C system," Metallurgical and Materials Transactions A, vol. 35, no. 5, pp. 1565-1577, 2004.

[14] H. Beladi, G. L. Kelly, and P. D. Hodgson, "Ultrafine grained structure formation in steels using dynamic strain induced transformation processing," Metallurgical and Materials Transactions: A, vol. 33, pp. 1019-1026, 2002.

[15] L. Sun, K. Muszka, B. P. Wynne, and E. J. Palmiere, "Effect of strain path on dynamic strain-induced transformation in a microalloyed steel," Acta Materialia, vol. 66, pp. 132-149, 2014. 

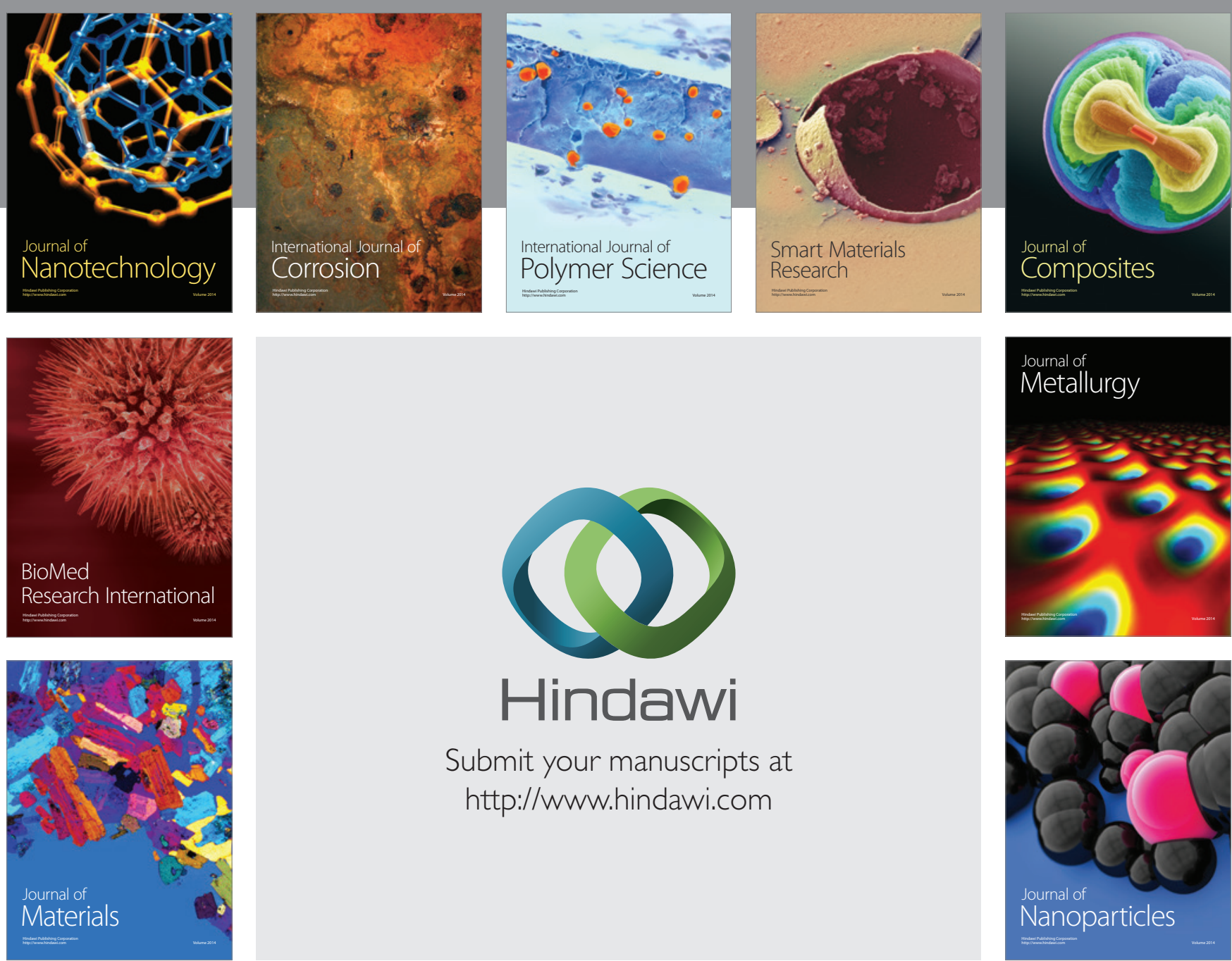

\section{Hindawi}

Submit your manuscripts at

http://www.hindawi.com

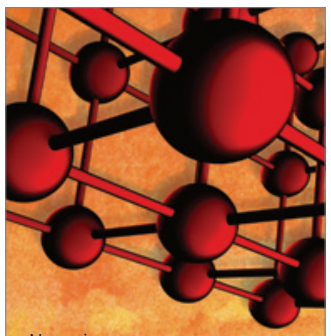

Materials Science and Engineering
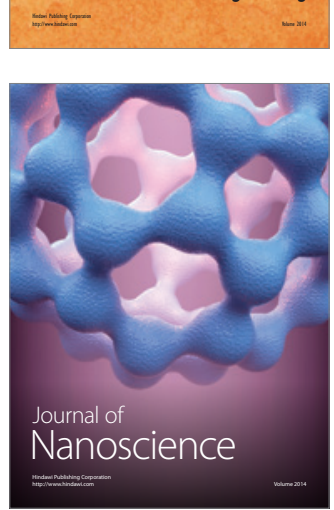
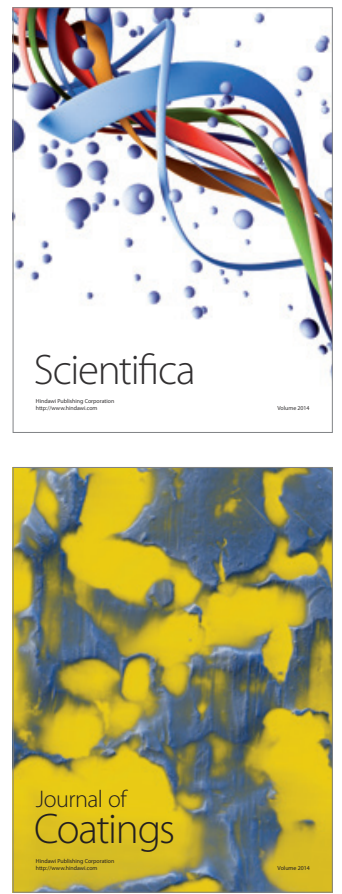
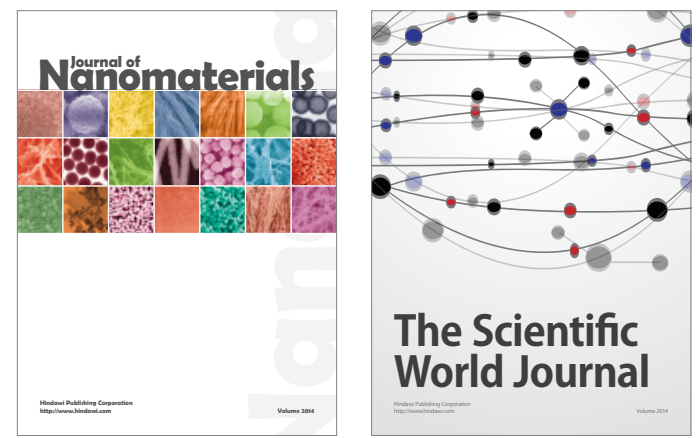

The Scientific World Journal
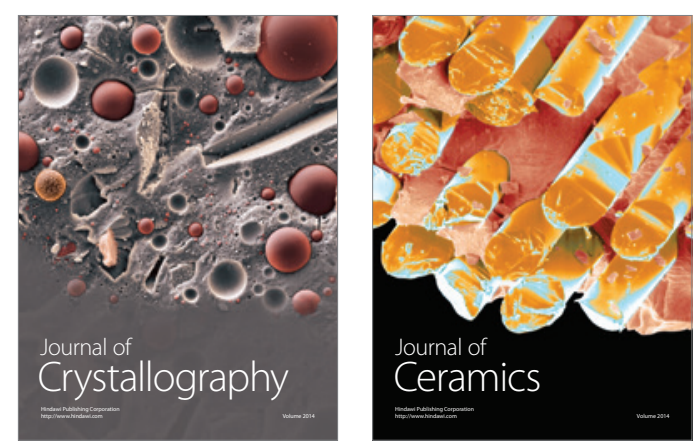
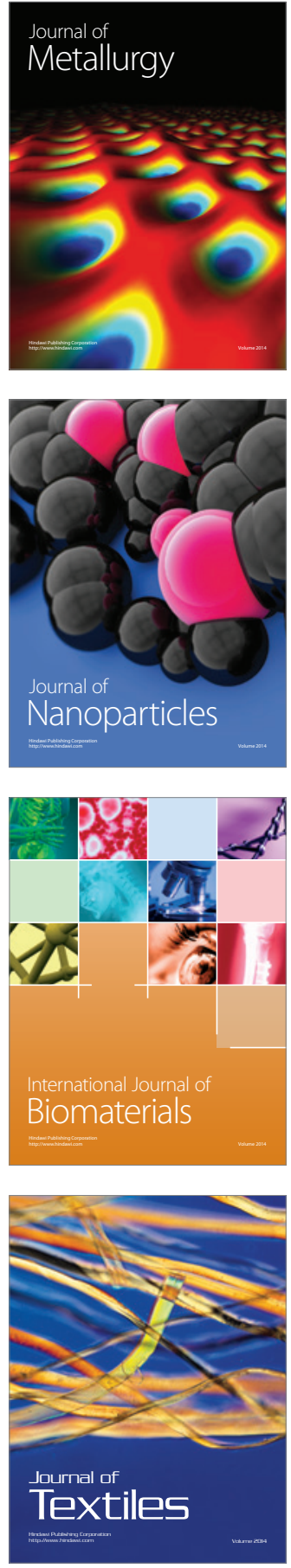